\title{
Accessing Value-in-Use Information by Integrating Social Platforms into Service Offerings
} Ville Eloranta and Juho-Ville Matveinen

\author{
"The new services insight is to observe customers in their" \\ environment, not yours, from an anthropological or \\ behavioral point of view.
}

\author{
Henry Chesbrough \\ Organizational theorist
}

\begin{abstract}
This article proposes a new approach for assessing the value derived from using a service offering (i.e., value-in-use) through the utilization of "social platforms." We define a social platform as an adaptable digital service environment that enables the co-creation of value through social interactions with other service systems. By reviewing the relevant literature, detailed propositions are built based on the integration of theoretical concepts, thereby combining the literature on service-dominant logic, platforms, and social media. The primary argument of the article is that embedding social platforms in a company's services may result in more efficient retrieval and understanding of customer insights, better management of customer intelligence, and ultimately higher value-in-use.
\end{abstract}

\section{Introduction}

Recent discussion on the concept of customer value has turned the interest from exchange value toward the value derived from using an offering (e.g., Bowman \& Ambrosini, 2000). The primary reason is the rise of the service economy, and the discussion is most evidently present in the research stream of service-dominant logic (Vargo \& Lusch, 2004, 2008). It sees all exchange as service exchange - and intangibles such as skills, information, and knowledge as higher in importance than traditional tangible goods. The stream takes a dramatic stand in its fundamental propositions and only acknowledges the existence of value-in-use. The argument is based on the strategic-level relevance of the predominant role of interactivity, connectivity, and ongoing relationships in value creation (Lusch et al., 2007).

The use of various social media and collaboration tools has gained increasing attention in solving issues related to customer information (Albors et al., 2008; Kärkkäinen et al., 2012; Peppler \& Solomou, 2011). These tools are commonly viewed as part of digital platforms (e.g.,
Kietzmann et al., 2011). From the company perspective, the tools allow access to information on the actions performed with products and services and how customers perceive the offerings in their own social contexts. Research on the influence of social media on customer cocreation (i.e., active, creative, and social collaboration between actors such as suppliers and customers) suggests that the relationship among the co-creating customers as well as the relationship between the suppliers and the customers is highly affected by the increasing use of such social media technologies (Piller et al., 2012; Rishika et al., 2013).

The social media tools may offer interesting possibilities in assessing the value-in-use information, and companies are not yet using the tools to their full potential. We consider the reason behind this issue to be related to the fact that social media is commonly interpreted in isolation and viewed with too narrow a focus. As stated, the social media technologies are seen to be a part of digital platforms. However, the research focuses primarily on the social media technologies themselves, and excludes the rich scholarly knowledge on platforms. 


\section{Accessing Value-in-Use Information by Integrating Social Platforms into Service Offerings} Ville Eloranta and Juho-Ville Matveinen

Therefore, we integrate the concepts of platform and social media and define the combination as a more abstract concept called a "social platform". In social platforms, social media is merely an enabling technology and usage logic, not a solution itself. Furthermore, we propose that social platforms are, in fact, service systems themselves and that their practical applications could benefit considerably from integrating the servicedominant logic's systemic approach to "value-in-use" with the platform literature.

This article limits itself to elaborating on the concept of value-in-use, as service-dominant logic interprets it, and how firms can enhance the assessment of value-inuse information with social platforms. Thus, this article builds theoretical bridges between the literature streams of service-dominant logic, platforms, and social media by integrating them in order to produce new knowledge. The boundary object for the integration is the concept of value-in-use.

For practitioners, the article provides insights on why and how to connect social platforms to services. We argue that social platforms are not merely bidirectional communication tools, which they are often regarded as, or simple additions to products. We propose that social platforms should, instead, be embedded in the services and used to operate and orchestrate them.

The structure of this article is as follows. First, the theoretical concepts of value-in-use and social platforms are presented, after which the theoretical concepts are integrated and three propositions formed. Finally, examples of social platforms are presented and future research directions are suggested.

\section{Assessing Value-in-Use}

The concept of customer value is perhaps the most overused and misused term in the marketing and management sciences, and there are many overlapping categorizations and perceptions of the concept (e.g., Khalifa, 2004). Hence, the focus of this article is to concentrate solely on the concept of value-in-use (i.e., value not from exchange but from using an offering) defined by the research stream of service-dominant logic (Vargo \& Lusch, 2004). Although value-in-use is widely recognized, it is noteworthy how silent the leading scholars remain on the practical assessment methods of the phenomenon. In the literature, there seems to be a lack of well-defined and established methods to understand and to assess value-in-use (e.g., Grönroos, 2008; Ostrom et al., 2010). This observation is of special importance, because the scholars have identified that existing quality and satisfaction assessment methods do not fully meet all demands of the value-in-use concept and that there is a need for new tools (e.g., Macdonald et al., 2011). In following subsections, we present three theory-anchored requirements for those new methods.

Further extending the scope of assessment for value-inuse toward customers' actions

One of the fundamental premises of the service-dominant logic is that value is realized only when the customers actually use the offerings and that suppliers can merely offer value propositions (Vargo \& Lusch, 2004, 2008). This premise implies that, to acquire improved value-in-use information, the supplier must move further toward the customer and support the value-creation process more effectively. The leading authors agree that there is a need to extend the scope of service offering and value assessment to the customers' own consumption and usage processes (e.g., Ballantyne \& Varey, 2006; Grönroos, 2006; Payne et al., 2008). More specifically, suppliers must not only monitor and track value creation at the intersections of the supplier-customer processes but extend and even embed the marketing operations inside the customers' own internal value-generating operations (Grönroos, 2006). In essence, supporting the customer and facilitating the service usage is crucial (Grönroos, 2008).

Due to the growing embeddedness of the suppliers' actions and the heightened importance of interaction between all stakeholders involved in value creation (Ballantyne \& Varey, 2006), the focus enlargement also stresses the relevance of acquiring not only customerspecific but also relation-specific knowledge from all events occurring between the value co-creation parties (Ballantyne, 2004). In this process, the suppliers and customers become inseparable and learning from the interaction is important (Matthing et al., 2004). In addition, as these events form complex and volatile paths over time, it is important to take a longitudinal perspective to the development of value-in-use (Ballantyne, 2004; Macdonald et al., 2011).

\section{The importance of individual customer value-in-use insights}

The service-dominant logic literature stresses the high context-specificity of value-in-use; it is seen as a very individual experience, perceived via each customer's personal perspective (Vargo \& Lusch, 2004; 2008). Thus, the generalizations of value-in-use aiming to "get a big picture" may not yield the desired outcome: value-in- 


\section{Accessing Value-in-Use Information by Integrating Social Platforms into Service Offerings} Ville Eloranta and Juho-Ville Matveinen

use must be addressed as a subjectively judged (Grönroos \& Ravald, 2011), individual-level, context-sensitive concept.

According to scholars on the original service-dominant logic writings, the word context implies, in this case, the outcome, purpose, and objective that are achieved through the service (Vargo \& Lusch, 2004). These factors are unique to each customer and moderated by situational filters (Sandström et al., 2008). This view emphasizes the need for gaining deep and personal - even tacit - insights about the interactions to understand further the value-in-use and the antecedents of value-creation activities (Ballantyne \& Varey, 2006). The context sensitivity also implies that all possible usage contexts cannot be always known in advance. The suppliers must therefore assess value-in-use with methods that adapt to unanticipated usage scenarios and situations.

\section{The need for a networked approach for value-in-use}

Value-in-use is not perceived by the customer in isolation but with the omniscient perspectives of the entire ecosystem (Chandler \& Vargo, 2011). The dyadic co-creation between the supplier and customer appears to not to be enough, because the value of the service often depends on the offerings of other - possibly unknown actors. Therefore, the presence, role, and effects of offerings by third parties and other suppliers in value creation must be identified, understood, and ultimately facilitated. With suppliers, the main driver for this seems to be related to the high importance of the network capabilities of the provider (i.e., the provider's strength in accessing and making use of other suppliers) (Macdonald et al., 2011). In the case of customers, the network approach is crucial, because the value-creation experience seems to be a networked phenomenon itself; value-in-use is relational and subject to the customers' own network experiences and opinions. Edvardsson, Tronvoll, and Gruber (2011) refer to this phenomenon as value-in-social context.

\section{Toward Social Platforms}

Platform research, along with platform thinking, have gained considerable traction during the past two decades, during which the concept has matured from the context of physical products and technologies into abstract business environments (Eisenmann et al., 2006; Cusumano \& Gawer, 2002, 2008; Meyer et al., 1997; Rochet \& Tirole, 2003; Sawhney, 1998). Originally, platforms were perceived only as bundles of standard components around which actors such as buyers and sellers coordinated their efforts (e.g., Bresnahan \& Greenstein,
1999). Later research (e.g., Eisenmann et al., 2006) suggests that platforms are products and services that bring together groups of users in two-sided networks. Thus, the focus of platforms moved to providing the infrastructure and rules facilitating the transactions. Recently, it has been concluded (e.g., Nishino et al., 2012) that platforms are, in essence, comprehensive strategies that provide business models upon which service providers, consumers, and manufacturers can interact. Hence, viewed from the service-dominant logic approach, the latest writings tend to see platforms as service systems that are dynamic configurations of resources that enable the co-creation of value with other service systems through shared information (cf. Maglio et al., 2008).

What does the widened scope and especially the service system approach mean for the platform concept in practice? Edvardsson and Olsson (1996) suggest that service systems should be designed to support co-creation so that the customers should not only participate but actively contribute to the process. In practice, this interaction is carried out by adapting the service process to the logic of the customers' behaviour, requiring a thorough understanding of the customers' needs and expectations. In a platform context, the implication is that reciprocal processes must be employed as part of the platform for the customers to be involved in the service process as co-creators of the customer experience (cf. Chesbrough, 2011a). Furthermore, research by Smedlund (2012) attempts to establish a connection between the current theories in service sciences and the literature stream of platforms and supports the notion that value creation relies ultimately upon the end user and involves high levels of interaction among actors participating on the platform, often through flexible front ends (Chesbrough, 2011b).

\section{The role of social media and value co-creation in digital platforms}

Because few platform leaders can manage to create complete systems and all the complements themselves, collaboration between actors is needed to enhance complementary innovation (Cusumano \& Gawer, 2002). For this reason, platforms are not under the full control of the company maintaining the platform, so strategies for managing the industry-wide network, as well as for facilitating the value co-creation in platforms, are needed. The traditional approach has addressed these needs through pricing and structure (Eisenmann et al., 2006; Evans, 2003; Rochet \& Tirole, 2003). However, as platforms are moving more to digital environments, companies wishing to enhance their 


\section{Accessing Value-in-Use Information by Integrating Social Platforms into Service Offerings} Ville Eloranta and Juho-Ville Matveinen

service platforms are seeking new ways of providing incentives for collaboration.

Social media technologies applied in the context of platforms could provide a new kind of venue for companies to facilitate interactions with actors in their service networks. Andzulis, Panagopoulos, and Rapp (2012) define social media as "the technological component of the communication, transaction, and relationship building functions of a business, which leverages the network of customers and prospects to promote value co-creation." Currently, there is a plethora of social media technologies, such as blogs, collaborative projects, social networking sites, content communities, virtual social worlds, and virtual game worlds, all representing different types of networked environments and channels that enable people, communities, and organizations to connect and share information (Kaplan \& Haenlein, 2010). Social media should therefore be viewed as the whole operating logic behind services that provides the means for social interactions between various actors in a network.

Social media and various methods of co-design may be used to engage companies and customers in collaborative innovation (Piller et al., 2012). Research by Agnihotri and colleagues (2012) also suggests that the presence of social content enablers (e.g., collaborative projects) and social network enablers (e.g., social networking sites) can be used to manage and promote the co-creation of value among actors. Social media technologies enable organizations to listen to their customers and analyze their experiences merely by monitoring and identifying issues, questions, and concerns voiced in their discussions (Andzulis et al., 2012). Consequently, the level of social participation influences the usability, relevance, and outcome of the acquired value-in-use information.

\section{Establishing consensus on social platforms}

Platforms are inherently service systems and, more specifically, environments that foster interactions among participants. Platforms serve to resolve issues of value co-creation and allow even unintended end uses. They often rely on intelligent digital systems that appear as easy-to-use front ends that allow the users to be in control of information. When the modern view of platforms is viewed in light of the social media literature, it seems that value co-creation in platforms can be facilitated through social media technologies. Hence, to enrich the concept of the platform with the possibilities of social media technologies and to form a unified concept for the purposes of this study, we define a new combin- atory concept of the social platform. Formally, we define a social platform as an adaptable digital service environment that enables the co-creation of value through social interactions with other service systems.

\section{Integrating the Concepts of Value-in-Use and Social Platform}

The theory of service-dominant logic stresses the importance of extending the scope of assessment further toward customers' own actions as the suppliers and customers together co-create the value (Vargo \& Lusch, $2004,2008)$. Therefore, the aim of suppliers is to acquire invitations to take part in the customers' own internal usage processes and to understand the value-in-use for the customers to be able to engage in value co-creation more extensively (Ballantyne \& Varey, 2006; Grönroos, 2006; Payne et al., 2008). Consequently, relation-specific knowledge and a longitudinal perspective on the development of value-in-use were identified as relevant aspects of the issue (Ballantyne, 2004; Macdonald et al., 2011; Matthing et al., 2004).

Social platforms seem to support these requirements. Platforms engage and involve companies and customers in collaborative innovation (Piller et al., 2012) and empower all stakeholders to participate in the co-creation of the customer experience (Chesbrough, 2011a). In practice, platforms connect different suppliers and customers with innovative interfaces - as in Chesbrough's (2011b) flexible front ends - and discovering and forming unique capabilities (Smedlund, 2012).

Due to the ability and convention of the customers to spontaneously articulate their goals, purposes, and objectives, accompanied by feedback about the gained value, the social platform orchestrator can extend its reach to the users and receive information about the customers' actions on the platform and ultimately understand the value-in-use of the customers while facilitating the processes, if appropriate. In addition, as the whole supplier-user interaction path is stored in the accumulated usage history, the platform owner can acquire a longitudinal perspective on the customer's perceived value-in-use.

Social platforms are themselves, in essence, service systems representing dynamic configurations of resources that enable the co-creation of value with other service systems through shared information (Maglio et al., 2008). Thus, social platforms can be embedded in the actual service systems, which further enables the suppliers to integrate their operations into the customers' 


\section{Accessing Value-in-Use Information by Integrating Social Platforms into Service Offerings}

\section{Ville Eloranta and Juho-Ville Matveinen}

processes. However, we argue that the success of the social platform in meeting the requirements is moderated by the design of the platform. This is because the cocreation and the collection of value-in-use information are not attained unless customers find it meaningful to operate on the social platform.

\section{Proposition 1: Social platforms facilitate the disclosure of value-in-use information by enabling suppliers to embed their operations with customers' processes and thereby intensify co-creation among customers and suppliers.}

Social platforms provide in-depth information about individual customer value-in-use insights

According to scholars on service-dominant logic, context-sensitivity (i.e., the relationship to the customer's individual and situational objectives, purposes, and outcomes that are achieved through the service, as well as the environment in which the co-creation happens) is one of the most crucial issues when assessing valuein-use (Chandler \& Vargo, 2011; Grönroos \& Ravald, 2011; Vargo \& Lusch, 2004, 2008). This view emphasizes the need to acquire deep-enough insights about the personal and situational conditions and communicative as well to learn about the interactions involved in value creation (Ballantyne \& Varey, 2006; Sandström et al., 2008). In addition, the adaptability of the value-inuse assessment system in regard to unknown and unanticipated usage scenarios is seen as important (Ballantyne \& Varey, 2006; Vargo \& Lusch, 2008).

It seems that social media is able to facilitate both spontaneous and structured self-disclosure for its users. The utilization of diverse social media technologies enables social platforms to foster varying degrees of intimacy and immediacy providing an environment for rich selfpresentation (Kaplan \& Haenlein, 2010). Placed in the context of value-in-use assessment, the implication is that social platforms can provide in-depth information about the users and their experiences with the products and services. Furthermore, if platforms are, as described earlier, embedded in the service systems themselves, the social platforms reveal how individual users actually use the solutions and thereby disclose the actual usage scenarios, value-creation activities, and related contextual factors.

Social platforms are not confined or restricted environments and may therefore adapt to meet the unanticipated needs of the surrounding system (Cusumano \& Gawer, 2002). Moreover, research by Gawer \& Cusumano (2008) acknowledges that social platforms enable actors to connect to or to build upon the system and allow even unintended end uses. Based on these arguments, social platforms appear to be well-adapting service systems suitable for acquiring value-in-use information from both planned and unanticipated customer usage settings but also for supporting the value co-creation in those scenarios.

\section{Proposition 2: The ability of social platforms to promote structured and context-sensitive self-disclosure, and the ability to adapt to the surrounding systems, en- hance and facilitate the acquisition of value-in-use in- formation in both planned and unanticipated usage settings.}

\section{A networked approach for value-in-use information is natural for social platforms}

Theory on the assessment of value-in-use emphasizes the relevance of adopting a network approach to value creation and the analysis of use-value, as well as moving beyond the dyadic supplier-customer relationships (Ballantyne \& Varey, 2006; Chandler \& Vargo, 2011; Maglio et al., 2008). The scholars underline the importance of understanding the actor-offering network where the value-in-use experience takes place (Chandler \& Vargo, 2011; Edvardsson et al., 2011). Extending the perspective to the network level makes it possible to identify and orchestrate multi-faceted relationship issues concerning the suppliers, the customers, and third parties (Chandler \& Vargo, 2011). It also enables and facilitates completely new ways of value creation.

Social platforms allow different types of collaboration to emerge depending on the level of effort put into digital content creation and the options for network-based interactions. Social network enablers (i.e., push-type technologies such as content communities) and social content enablers (i.e., pull-type technologies such as collaborative projects) as part of social platforms, allow the customers to influence their degree of involvement as well as the type of information acquired and shared (Agnihotri et al., 2012). Therefore, the presence of social content enablers and social network enablers can promote the co-creation of value among actors. The ability of platforms to adapt to the surrounding system has an influence on the degree of innovation and complements, the extent of modularity, relationships with external complementors, and the internal organization (Cusumano \& Gawer, 2002). Thus, social platforms themselves promote networked operations and thereby foster innovation and build relationships across organization boundaries - even in unique ways, as described earlier in reference to Smedlund (2012). Hence, we ar- 


\section{Accessing Value-in-Use Information by Integrating Social Platforms into Service Offerings}

\section{Ville Eloranta and Juho-Ville Matveinen}

gue that there is considerable potential for the platform orchestrator to organize the whole service system development and influence its direction.

Proposition 3: The networked approach of social platforms inherently allows for the collection of value-inuse information from multiple parties as well as the management of the service system.

\section{Concluding Discussion}

This article proposes a new approach for assessing the value derived from using a service offering (value-inuse) through the utilization of social platforms. We propose that embedding social platforms in the company's service offering would result in more efficient retrieval and understanding of context-aware individual-level insights about customer and third-party networks, better management of customer intelligence, and ultimately higher value-in-use for the whole service ecosystem. In addition, we argue that social platforms as well as social media technologies should not be treated as independent tools but should, instead, be embedded in the service systems. In theory, this approach means combining the concepts of service systems, platforms, and social platforms and forming a metatheory about them. We have begun this work by connecting the service-dominant logic's concept of value-in-use and social platforms, but this is just a starting point for more extensive research. In practice, social platforms should be embedded in the service systems themselves. That is, instead of "toolism", we would like to see more practical implementations of complete digital service systems.

Let us consider an example in the context of a factory automation system. It is relatively easy to remotely monitor the technical aspects of the system but the social and tacit side of value co-creation is left with less attention, although these factors have considerable influence on the experienced value-in-use. What would happen if a social platform was embedded into the automation system's operation logic? Given that using the social platform would actually be a natural part of the system management, the operator and system supplier could learn from comparing technical data and employee-toemployee interactions. Also, the social platform could reveal hidden structures and influencers deep inside the organizations. With modern analytics software already available for the common social media, the possibilities for organizational learning would be immense. Most importantly, the users would see only little overhead because the social platform would be the operations environment itself.
Another example can be conceptualized for the healthcare sector. Instead of a traditional appointment-based service, the physician could interact with the patient in real time, with the help of relatively inexpensive wearable device. The social platform would enable the physician to develop a closer relationship to the patient and follow their real-life operations - of course only with patient's consent. Hence, the physician would not be limited by the information the patient is able to explicate during an appointment but would be able to assess the real value-in-use information from the patient's reallife context. Moreover, the social platform would enable the combination of information from multiple sources such as sports trackers, calorie counters, and sleep meters, to name but a few. Therefore, social platforms could provide better patient care and also provide new opportunities for profitable business. To summarize, the social platform would enable a completely new kind of business model: health-as-a-service, and make it possible to reach entirely new levels of value for the patient.

Having presented all these promising ideas regarding the potential of social platforms in service business, it might be tempting to rush into developing platforms and implementing social media technologies into service offerings. However, practitioners need to be aware of the challenges involved and recall that many platform providers and owners fail to become platform leaders. In platforms, leadership can only be acquired by fostering collaboration between different actors, driving the platform innovation forward, and also securing the owner's benefits in the business model (e.g., Gawer \& Cusumano, 2008). The same argument is evident in the social media literature that stresses the active role of customers in the co-creation of value but also in influencing who orchestrates the brand experience (Hanna et al., 2011). In more abstract marketing literature, this situation has been approached, for example, with the term "channel multiplicity", which means that the leadership position in different channels has become "occasion-specific and user defined" (Van Bruggen et al., 2010). Thus, broad evidence asserts that setting up a new platform as merely a simple service extension is not enough: value co-creation should be comprehensively facilitated and benefits must be secured to all relevant stakeholders.

Fortunately, the platform literature does offer solutions to these questions. Moore (1993) identified cooperative actions (i.e., working with the market to design, promote, and innovate an expanding and self-renewing offering and vision) and competitive operations (i.e., 


\section{Accessing Value-in-Use Information by Integrating Social Platforms into Service Offerings} Ville Eloranta and Juho-Ville Matveinen

protecting the platform itself and the company's own incentives). More recently, Gawer and Cusumano (2008) advanced the discussion further by making a distinction between creating a new platform (i.e., "coring”) and creating competing offerings (i.e., "tipping”). In coring, the authors stressed the discovery of the systemic problem in the actor network and the role of platforms in solving the problem. With tipping, the authors referred to the development of unique and hard-to-imitate features, as well as to absorbing and bundling features from adjacent markets. Also, looking more towards the strategic management discussion, Eisenmann (2011) introduced the concept of "platform envelopment", referring to a company's attempt to integrate functionalities from competing platforms into its own environment.

Thus, these authors, in addition to many others, provide numerous abstract-level answers to the platform development and leadership issues, and hence pave the way for applications in practical social platform contexts. The social media literature has already widely assessed the challenges of user and actor engagement. Now, this discourse could be further integrated with the platform literature in order to address not only the potential of social platforms - the theme of this article - but also their orchestration.

\section{Acknowledgements}

This research was conducted in the Future Industrial Services (FutIS) research program, which is managed by the Finnish Metals and Engineering Competence Cluster (FIMECC) and jointly funded by the Finnish Funding Agency for Technology and Innovation (TEKES) as well as research institutes and companies involved in the FutIS program. Their support is gratefully acknowledged. In addition, we would like to thank Dr. Anssi Smedlund from Aalto University School of Science for valuable conceptual input.

\section{About the Authors}

Ville Eloranta, MSc (Tech), is a doctoral student in the Service Engineering and Management (SEM) research group at Aalto University School of Science, Finland. Ville joined academia in 2012 after seventeen years in digital service design business and seven years of entrepreneurship. Ville's research interests cover manufacturers' service infusion/servitization, service networks, and service platforms. Currently, he is focusing on studying the sources of competitive advantage in service networks and methods of agile service network orchestration.

Juho-Ville Matveinen, MSc (Tech), is a business designer at Diagonal, an acclaimed service design agency in Finland. His forte is organization development and the strategic planning of service ecosystems in addition to managing change as part of business development activities. He has a background in research at the Department of Industrial Engineering and Management at Aalto University School of Science, where he focused on researching digital service platforms and their application in business development. 


\section{Accessing Value-in-Use Information by Integrating Social Platforms into Service Offerings} Ville Eloranta and Juho-Ville Matveinen

\section{References}

Agnihotri, R., Kothandaraman, P., Kashyap, R., \& Singh, R. 2012. Bringing "Social" Into Sales: The Impact of Salespeople's Social Media Use on Service Behaviors and Value Creation. Journal of Personal Selling and Sales Management, 32(3): 333-348. http://dx.doi.org/10.2753/PSS0885-3134320304

Albors, J., Ramos, J.C., \& Hervas, J.L. 2008. New Learning Network Paradigms: Communities of Objectives, Crowdsourcing, Wikis and Open source. International Journal of Information Management, 28(3): 194-202.

http://dx.doi.org/10.1016/j.ijinfomgt.2007.09.006

Andzulis, J., Panagopoulos, N., \& Rapp, A. 2012. A Review of Social Media and Implications for the Sales Process. Journal of Personal Selling and Sales Management, 32(3): 305-316.

http://dx.doi.org/10.2753/PSS0885-3134320302

Ballantyne, D. 2004. Dialogue and its Role in the Development of Relationship Specific Knowledge. Journal of Business \& Industrial Marketing, 19(2): 114-123.

http://dx.doi.org/10.1108/08858620410523990

Ballantyne, D. \& Varey, R. 2006. Creating Value-in-Use Through Marketing Interaction: The Exchange Logic of Relating, Communicating and Knowing. Marketing Theory, 6(3): 335-348. http://dx.doi.org/10.1177/1470593106066795

Bowman, C. \& Ambrosini, V. 2000. Value Creation Versus Value Capture: Towards a Coherent Definition of Value in Strategy. British Journal of Management, 11(1): 1-15. http://dx.doi.org/10.1111/1467-8551.00147

Bresnahan, T.F. \& Greenstein, S. 1999. Technological Competition and the Structure of the Computer Industry. The Journal of Industrial Economics, 47(1): 1-40.

http://dx.doi.org/10.1111/1467-6451.00088

Chandler, J.D. \& Vargo, S.L. 2011. Contextualization and Value-inContext: How Context Frames Exchange. Marketing Theory, 11(1): $35-49$.

http://dx.doi.org/10.1177/1470593110393713

Chesbrough, H. 2011a. Bringing Open Innovation to Services. MIT Sloan Management Review, 52(2): 85-90.

Chesbrough, H. 2011b. Open Services Innovation: Rethinking Your Business to Grow and Compete in a New Era. Jossey Bass, San Francisco.

Cusumano, M. \& Gawer, A. 2002. The Elements of Platform Leadership. MIT Sloan Management Review, 43(3): 51-58.

Edvardsson, B. \& Olsson, J. 1996. Key Concepts for New Service Development. The Service Industries Journal, 16(2): 140-164. http://dx.doi.org/10.1080/02642069600000019

Edvardsson, B., Tronvoll, B., \& Gruber, T. 2011. Expanding Understanding of Service Exchange and Value Co-Creation: A Social Construction Approach. Journal of the Academy of Marketing Science, 39(2): 327-339. http://dx.doi.org/10.1007/s11747-010-0200-y

Eisenmann, T., Parker, G., \& Van Alstyne, M.W. 2006. Strategies for Two-Sided Markets. Harvard Business Review, 84(10): 92-104.

Eisenmann, T., Parker, G., \& Van Alstyne, M.W. 2011. Platform Envelopment. Strategic Management Journal, 32(12): 1270-1285. http://dx.doi.org/10.1002/smj.935
Evans, D.S. 2003. Some Empirical Aspects of Multi-sided Platform Industries. Review of Network Economics, 2(3): 1-19. http://dx.doi.org/10.2202/1446-9022.1026

Gawer, A. \& Cusumano, M.A. 2008. How Companies Become Platform Leaders. MIT Sloan Management Review, 49(2): 28-35.

Grönroos, C. 2006. Adopting a Service Logic for Marketing. Marketing Theory, 6(3): 317-333. http://dx.doi.org/10.1177/1470593106066794

Grönroos, C. 2008. Service Logic Revisited: Who Creates Value? And Who Co-Creates? European Business Review, 20(4): 298-314. http://dx.doi.org/10.1108/09555340810886585

Grönroos, C. \& Ravald, A. 2011. Service as Business Logic: Implications for Value Creation and Marketing. Journal of Service Management, 22(1): 5-22. http://dx.doi.org/10.1108/09564231111106893

Hanna, R., Rohm, A., \& Crittenden, V.L. 2011. We're All Connected: The Power of the Social Media Ecosystem. Business Horizons, 54(3): 265-273. http://dx.doi.org/10.1016/j.bushor.2011.01.007

Kaplan, A.M. \& Haenlein, M. 2010. Users of the World, Unite! The Challenges and Opportunities of Social Media. Business Horizons, 53(1): 59-68. http://dx.doi.org/10.1016/j.bushor.2009.09.003

Kärkkäinen, H., Jussila, J., \& Leino, H. 2012. Learning from and with Customers with Social Media: A Model for Social Customer Learning. International Journal of Management, Knowledge and Learning, 1(1): 5-25.

Khalifa, A.S. 2004. Customer Value: A Review of Recent Literature and an Integrative Configuration. Management Decision, 42(5): 645-666. http://dx.doi.org/10.1108/00251740410538497

Kietzmann, J.H., Hermkens, K., McCarthy, I.P., \& Silvestre, B.S. 2011. Social Media? Get Serious! Understanding the Functional Building Blocks of Social Media. Business Horizons, 54(3): 241-251. http://dx.doi.org/10.1016/j.bushor.2011.01.005

Lusch, R.F., Vargo, S.L., \& O'Brien, M. 2007. Competing through Service: Insights from Service-Dominant Logic. Journal of Retailing, 83(1): 5-18.

http://dx.doi.org/10.1016/j.jretai.2006.10.002

Macdonald, E.K., Wilson, H., Martinez, V., \& Toossi, A. 2011. Assessing Value-in-Use: A Conceptual Framework and Exploratory Study. Industrial Marketing Management, 40(5): 671-682.

http://dx.doi.org/10.1016/j.indmarman.2011.05.006

Maglio, P.P., Vargo, S.L., Caswell, N., \& Spohrer, J. 2008. The Service System Is the Basic Abstraction of Service Science. Information Systems and e-Business Management, 7(4): 395-406.

http://dx.doi.org/10.1007/s10257-008-0105-1

Matthing, J., Sanden, B., \& Edvardsson, B. 2004. New Service Development: Learning from and with Customers. International Journal of Service Industry Management, 15(5): 479-498. http://dx.doi.org/10.1108/09564230410564948

Meyer, M.H., Tertzakian, P., \& Utterback, J.M. 1997. Metrics for Managing Research and Development in the Context of the Product Family. Management Science, 43: 88-111. http://dx.doi.org/10.1287/mnsc.43.1.88 


\section{Accessing Value-in-Use Information by Integrating Social Platforms into Service Offerings Ville Eloranta and Juho-Ville Matveinen}

Moore, J.F. 1993. Predators and Prey: A New Ecology of Competition. Harvard Business Review, 71(3): 75-86.

Nishino, N., Wang, S., Tsuji, N., Kageyama, K., \& Ueda, K. 2012. Categorization and Mechanism of Platform-Type Product-Service Systems in Manufacturing. CIRP Annals - Manufacturing Technology, 61(1): 391-394. http://dx.doi.org/10.1016/j.cirp.2012.03.053

Ostrom, A.L., Bitner, M.J., Brown, S.W., Burkhard, K. a., Goul, M., Smith-Daniels, V., Demirkan, H., et al. 2010. Moving Forward and Making a Difference: Research Priorities for the Science of Service. Journal of Service Research, 13(1): 4-36. http://dx.doi.org/10.1177/1094670509357611

Payne, A.F., Storbacka, K., \& Frow, P. 2008. Managing the Co-Creation of Value. Journal of the Academy of Marketing Science, 36(1): 83-96. http://dx.doi.org/10.1007/s11747-007-0070-0

Peppler, K.A. \& Solomou, M. 2011. Building Creativity: Collaborative Learning and Creativity in Social Media Environments. On the Horizon, 19(1): 13-23. http://dx.doi.org/10.1108/10748121111107672

Piller, F., Vossen, A., \& Ihl, C. 2012. From Social Media to Social Product Development: The Impact of Social Media on Co-Creation of Innovation. Die Unternehmung, 65(1): 7-27. http://ssrn.com/abstract=1975523

Rishika, R., Kumar, A., Janakiraman, R., \& Bezawada, R. 2013. The Effect of Customers' Social Media Participation on Customer Visit Frequency and Profitability: An Empirical Investigation. Information Systems Research, 24(1): 108-127. http://dx.doi.org/10.1287/isre.1120.0460
Rochet, J.-C. \& Tirole, J. 2003. Platform Competition in Two-Sided Markets. Journal of the European Economic Association, 1(4): 990-1029.

http://dx.doi.org/10.1162/154247603322493212

Sandström, S., Edvardsson, B., Kristensson, P., \& Magnusson, P. 2008. Value in Use through Service Experience. Managing Service Quality, 18(2): 112-126.

http://dx.doi.org/10.1108/09604520810859184

Sawhney, M.S. 1998. Leveraged High-Variety Strategies: From Portfolio Thinking to Platfrom Thinking. Journal of the Academy of Marketing Science, 26: 54-61. http://dx.doi.org/10.1177/0092070398261006

Smedlund, A. 2012. Value Cocreation in Service Platform Business Models. Service Science, 4(1): 79-88. http://dx.doi.org/10.1287/serv.1110.0001

Van Bruggen, G.H., Antia, K.D., Jap, S.D., Reinartz, W.J., \& Pallas, F. 2010. Managing Marketing Channel Multiplicity. Journal of Service Research, 13(3): 331-340. http://dx.doi.org/10.1177/1094670510375601

Vargo, S.L. \& Lusch, R.F. 2004. Evolving to a New Dominant Logic for Marketing. Journal of Marketing, 68: 1-17. http://dx.doi.org/10.1509/jmkg.68.1.1.24036

Vargo, S.L. \& Lusch, R.F. 2008. Service-Dominant Logic: Continuing the Evolution. Journal of the Academy of Marketing Science, 36(1): $1-10$. http://dx.doi.org/10.1007/s11747-007-0069-6

Keywords: platforms, social media, value-in-use, service systems, service-dominant logic 